УДК 631.9

DOI: 10.36718/1819-4036-2019-11-24-29
О.А. Власенко, Н.Л. Кураченко, О.А. Ульянова,

Е.Ю. Казанова, В.В. Казанов, Ф. Халилзода

\title{
СТРУКТУРА И ДИНАМИКА ЗАПАСОВ РАСТИТЕЛЬНОГО ВЕЩЕСТВА В АГРОЦЕНОЗЕ РЫЖИКА ПОСЕВНОГО*
}

\section{O.A. Vlasenko, N.L. Kurachenko, O.A. Ulyanova, E. Yu. Cazanova, V.V.Cazanov, F. Khalilzoda \\ THE STRUCTURE AND DYNAMICS OF THE RESOURCES OF PLANT SUBSTANCE IN AGROCENOSES OF SOWING CAMELINA}

Власенко О.А. - канд. биол. наук, доц. каф. почвоведения и агрохимии Красноярского государственного аграрного университета, г. Красноярск. E-mail: ovlasenk007@mail.ru

Кураченко Н.Л. - д-р биол. наук, проф., зав. кафр. почвоведения и агрохимии Красноярского государственного аграрного университета, г. Красноярск.

E-mail: kurachenko@mail.ru

Ульянова О.А. - д-р биол. наук, профр. каф. почвоведения и агрохимии Красноярского государственного аграрного университета, г. Красноярск. E-mail: kora64@mail.ru

Казанова Е.Ю. - магистрант каф. почвоведения и агрохимии Красноярского государственного аграрного университета, г. Красноярск.

E-mail: ovlasenk007@mail.ru

Казанов В.В. - асп. каф. почвоведения и агрохимии Красноярского государственного аграрного университета, г. Красноярск.

E-mail: ovlasenk007@mail.ru

Халилзода Ф. - студ. 4-го курса Красноярского государственного аграрного университета, г. Красноярск.

E-mail: ovlasenk007@mail.ru

Цель исследования - изучить структуру и запасы растительного вещества в агроценозе рьжика посевного (Camelinasativa (L.) Crantz), воздельваемого на маслосемена в Канской лесостепи. Почвенный покров участка исследования представлен сочетанием агрочерноземов глинисто-иллювиальных типичных, агрочерноземов глинисто-иллювиальных оподзоленных мощных $и$ агрочерноземов криогенно-
Vlasenko O.A. - Cand. Biol. Sci., Assoc. Prof., Chair of Soil Science and Agrochemistry, Krasnoyarsk State Agrarian University, Krasnoyarsk.

E-mail: ovlasenko07@mail.ru

Kurachenko N.L. - Dr. Biol. Sci., Prof., Head, Chair of Soil Science and Agrochemistry, Krasnoyarsk State Agrarian University, Krasnoyarsk.

E-mail: kurachenko@mail.ru

Ulyanova O.A. - Dr. Biol. Sci., Prof., Chair of Soil Science and Agrochemistry, Krasnoyarsk State Agrarian University, Krasnoyarsk.

E-mail: kora64@mail.ru

Kazanova E.Yu. - Magistrate Student, Chair of Soil Science and Agrochemistry, Krasnoyarsk State Agrarian University, Krasnoyarsk.

E-mail: ovlasenko07@mail.ru

Kazanov V.V. - Post-Graduate Student, Chair of Soil Science and Agrochemistry, Krasnoyarsk State Agrarian University, Krasnoyarsk.

E-mail: ovlasenko07@mail.ru

Khalilzoda F. - 4-Year Student, Krasnoyarsk State Agrarian University, Krasnoyarsk.

E-mail: ovlasenk007@mail.ru

мицеллярных маломощных, занимающих микроповышения. Надземное растительное вещество определяли методом укосов, подземное до глубины 40 см - методом монолитов. В составе надземного растительного вещества выделяли фритомассу культуры и сорняков и надземную мортмассу. В структуре подземного растительного вещества выделяли корни, крупную и мелкую мортмассу. Запасы фрракций

*Исследование выполнено при фринансовой поддержке Российского ффонда фундаментальных исследований, Правительства Красноярского края, Красноярского краевого фонда науки и обществом с ограниченной ответственностью 000 "ОПХ "Солянское"», в рамках научного проекта «Исследование механизмов формирования пула легкоминерализуемого органического вещества в агрогеннопреобразованных почвах Канской лесостепи». 
доводили до воздушно-сухого состояния и рассчитьвали их запасы. Результаты исследования показали, что максимальный запас фритомассы рыжика сфрормировался в фразу созревания плодов и семян и составил $2,9 \mathrm{~m} / 2$. В это же время обнаружены максимальные запасы корней в слое 0-40 см, которые составили 2,1 $\mathrm{m} / 2$. Запасы фоитомассы сорняков не превышали $1,0 \mathrm{~m} / 2 а$. Пополнение запасов надземной мортмассы происходило благодаря пожнивным остаткам предшествующих культур и свежему опаду воздельваемой культуры. Снижение запасов этой фракции в течение вегетации связано с процессами ее разложения и перехода в состав подземной мортмассы. В среднем за вегетацию запасы надземной мортмассы в агроценозе рыжика составили 0,4 m/2a. Запасы подземной мортмассы, являясь источником для минерализации и образования гумусовых веществ, имели волнообразньй характер динамики во время вегетащии. В среднем общие запасы подземной мортмассы в слое 0-40 см составили 7,6 m/2а, в том числе запасы мелкой мортмассы - 2,7 /га. При этом в слое почвы 0 20 см было сосредоточено 65-81 \% корней, крупной и мелкой мортмассы.

Ключевье слова: рыжик посевной, Camelinasativa (L.) Crantz, растительное вещество, фрuтомасса, корни, мортмасса.

The research purpose was to study the structure and plant matter stocks in the agrocenosis of Camelina sativa (L.) Crantz, cultivated for oilseeds in the Kansk forest-steppe. The soil cover in the study site was represented by the combination of typical clay and illuvial agrochernozems, clay and illuvial podzolized agrochernozems and cryogenic and micellar low-power agrochernozems occupying microincreases. Aboveground plant matter was determined by mowing method, underground to the depth of $40 \mathrm{~cm}$ - by monoliths method. As a part of elevated vegetable substance the phytomass of culture and weeds and an elevated mortmass were allocated. Roots, large and small mortmass were distinguished in underground plant matter structure. All fractions were brought to an air-dry state and then reserves were calculated. The study results showed that the maximum camelina phytomass stock was formed in fruit and seed germination phase and amounted to 2.9 thectare. At the same time, maximum root reserves were found in the 0-40 cm layer, which made 2.1 t/hectare. Weed stocks phytomass did not exceed 1.0 t/ hectare.
Above-ground mortmass accumulation occurred due to crop residues of previous yield and fresh litter of cultivated crop. The decrease in stocks of this fraction during vegetation was connected with the processes of its decomposition and transition to structure of underground mortmass. On average, during vegetation season aboveground mortmass reserves of camelina in the agrocenosis were $0.4 t$ / hectare. Underground mortmass reserves, being the source for mineralization and humic substances formation, had wave character of dynamics during vegetation season. On average, the total underground mortmass reserves in 0-40 cm layer were 7.6 t/hectare, including shallow mortmass reserves -2.7 t/hectare. At the same time, $65-81 \%$ of roots of large and small mortmass were concentrated in a soil layer of 0-20 cm.

Keywords: camelina (Camelinasativa (L.) Crantz), plantmatter, phytomass, roots, mortmass.

Введение. Источники органической части почвы - растительные и другие органические остатки, поступающие в нее. В целинных почвах это остатки естественной растительности, отмирающие микроорганизмы и почвенная фрауна, являющаяся как исходным материалом для образования гумуса, так и стимулятором самого процесса гумусообразования [1]. В пахотных почвах существенное значение в качестве источника гумуса имеют органические удобрения, пожнивные остатки, а также растительные остатки, поступающие в почву при выращивании культур. Динамика запасов растительного вещества в агроценозах зависит от генетической природы культур, погодных условий, обеспеченности почвы запасами влаги и питательных элементов [2-4].

Цель исследования: изучить структуру и запасы растительного вещества в агроценозе рыжика посевного (Camelina sativa (L.) Crantz), возделываемого на маслосемена.

В задачи исследования входило определить динамику запасов фрракций надземного и подземного растительного вещества в слое 0-20 и 20-40 cM.

Объекты и методы исследования. Исследование выполнено в 2019 г. в Канской лесостепи Канско-Рыбинского геоморфологического округа в землепользовании ООО «ОПХ "Солянское"». На участке пашни зернопарового севооборота (пар - пшеница - горохоовсяная травосмесь - рыжик) площадью 5 га проведено изу- 
чение запасов растительного вещества в агроценозе рыжика посевного сорта Ужурский. Этот участок отличается комплексностью почвенного покрова и представлен сочетанием агрочерноземов глинисто-иллювиальных типичных, агрочерноземов глинисто-иллювиальных оподзоленных мощных и агрочерноземов криогенно-мицеллярных маломощных, занимающих микроповышения. Агрочерноземы имеют высокое содержание гумуса (6-9 \%), высокую сумму обменных оснований (51-64 ммоль/100 г), нейтральную и слабощелочную реакцию среды (pH 6,5-7,3).

Обработка почвы для возделывания рыжика состояла из осенней вспашки плугом ПСКУ-8, весной - ранневесеннего боронования и предпосевной культивации. Посев рыжика производили во второй декаде мая. При возделывании рыжика на маслосемена (в конце июня - начале июля) применялись средства защиты, стимуляторы роста и азотные подкормки: Табу, ВСК (6 л/т) Миура $(0,8$ л/га) + гуминатрин масличный (2,2 л/га) - Брейк, МЭ (0,06 л/га) + магниевая селитра (3 кг/га).

Надземное и подземное растительное вещество отбирали в 4-кратной повторности в следующие фразы роста и развития рыжика: посев прорастание семян (16.05.2019), рост в длину (18.06.2019), цветение - развитие плодов (18.07.2019), созревание плодов и семян (29.08.2019). Надземное растительное вещество учитывали методом укосов, площадь укоса - 0,25 м². Далее его разбирали на фрракции: фитомассу культуры, фитомассу сорняков, надземную мортмассу (отмершие и опавшие на поверхность почвы части растений). Подземное растительное вещество отбирали одновременно с надземным в те же сроки и на тех же пробных площадях методом монолитов на глубину 0-20 и 20-40 cм. Площадь монолита - 0,02 м². Монолиты отмыва- ли от почвы в проточной воде на сите с диаметром ячеек 0,25 мм. Отмытое подземное растительное вещество разбирали на фракции: корни, крупную мортмассу > 0,5 мм, мелкую мортмассу $<0,5$ мм. Все фрракции растительного вещества доводили до воздушно-сухого состояния, взвешивали и определяли запасы.

Результаты исследования и их обсуждение. Погодные условия 2019 г. на территории Канской лесостепи были благоприятными для большинства сельскохозяйственных культур. Период вегетации характеризовался как теплый и влажный. В июне в фазу роста в длину запасы надземной фитомассы рыжика составили 0,39; запасы фитомассы сорняков - 0,07 т/га (табл. 1). После обработки посевов баковой смесью гербицидов запасы фиитомассы сорняков снизились и не превысили 1 т/га за всю вегетацию. К июлю, после обильных осадков, в фазу цветения - развития плодов запасы фритомассы культуры существенно возросли до 2,0 т/га, что обусловлено ее биологическими особенностями. К августовскому сроку в период созревания плодов и семян запасы фитомассы достигли максимума - 2,94 т/га.

Запасы надземной мортмассы в начале вегетации $(0,55$ т/га) характеризуют количество растительных остатков предшествующей культуры горохоовсяной смеси, которые представлены стеблями, листьями и узлами кущения. Этот запас пожнивных остатков постепенно переходит в подземный блок после предпосевной обработки почвы и посева культур. К июню запасы надземной мортмассы сократились до минимального уровня - 0,17 т/га. Далее в течение вегетации надземные части растений желтеют, отмирают, опадают на почву, формируя новый запас надземной мортмассы, который к августу снова увеличился до 0,49 т/га.

\section{Таблица 1}

\section{Запасы надземного растительного вещества в агроценозе рыжика посевного, т/га}

\begin{tabular}{|l|c|c|c|}
\hline $\begin{array}{c}\text { Срок } \\
\text { отбора }\end{array}$ & $\begin{array}{c}\text { Фитомасса культуры } \\
(\mathrm{X} \pm \mathrm{Sx})^{*}\end{array}$ & $\begin{array}{c}\text { Фитомасса сорняков } \\
(\mathrm{X} \pm \mathrm{Sx})\end{array}$ & $\begin{array}{c}\text { Надземная мортмасса } \\
(\mathrm{X} \pm \mathrm{Sx})\end{array}$ \\
\hline Май & 0 & 0 & $0,55 \pm 0,08$ \\
\hline Июнь & $0,39 \pm 0,03$ & $0,07 \pm 0,09$ & $0,17 \pm 0,02$ \\
\hline Июль & $2,01 \pm 0,11$ & $0,22 \pm 0,14$ & $0,35 \pm 0,07$ \\
\hline Август & $2,94 \pm 0,17$ & $0,76 \pm 0,23$ & $0,49 \pm 0,04$ \\
\hline
\end{tabular}

*Здесь и далее: X - средняя; Sx - стандартная ошибка средней. 
В исследуемом агроценозе в структуре надземного растительного вещества к августовскому сроку преобладала фитомасса культуры, ее доля составила $70 \%$, запасы фитомассы сорняков - $18 \%$, надземной мортмассы - $12 \%$ от всех запасов надземного растительного вещества (рис. 1). Таким образом, фитомасса куль- туры занимает значительную долю в структуре надземного растительного вещества. Некоторая часть запасов фитомассы отчуждается с урожаем, но большая ее часть измельчается и остается на поверхности, после чего в надземной части агроценозов остаются значительные запасы мортмассы.

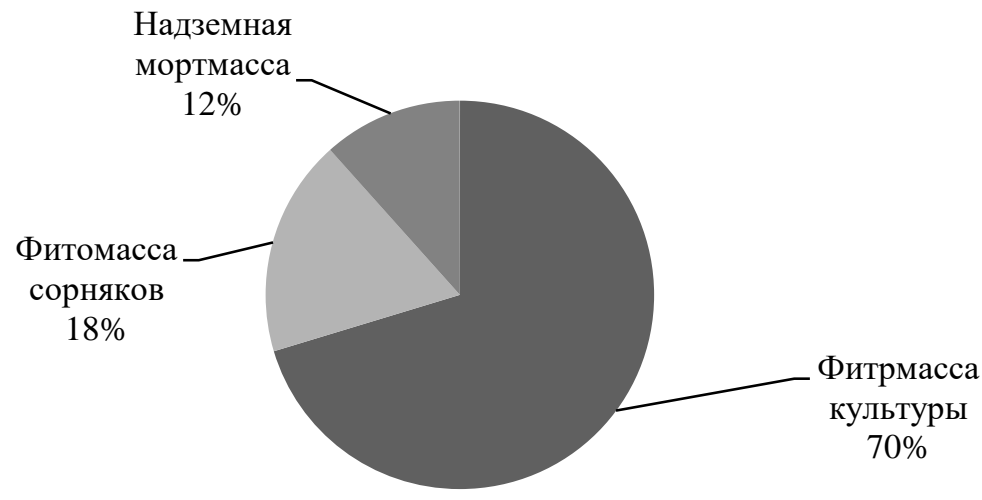

Puc. 1. Структура надземного растительного вещества в агроценозе рыжика посевного

Подземное растительное вещество представлено корнями и мортмассой, при этом мортмасса разделяется на крупную (> 0,5 мм) и мелкую (< 0,5 мм) фракции (табл. 2). Такое разделение необходимо с точки зрения выделения пула лабильного органического вещества, которое представлено мелкими, частично гумисрицированными растительными остатками и микробной биомассой. Крупные остатки и корни являются источником формирования запасов мелкой мортмассы (лабильного органического вещества) почвы. Поскольку корни культур проникают на достаточно большую глубину, фрормирование запасов подземного растительного вещества было изучено в слоях 0-20 и 20-40 см. Так же как и запасы надземной фритомассы, запасы корней постепенно увеличиваются по мере роста культуры. Причем большая часть корней сосредоточена в слое 0-20 см, особенно это становится заметно к концу вегетации. Корни играют очень важную роль в формировании запасов крупной и мелкой мортмассы, а также гумусовых веществ почвы. В пик прироста фитомассы запасы корней рыжика в слое 0-20 см составили 1,4 т/га, а в слое 20-40 см - 0,68 т/га. Таким образом, в слое почвы 0-20 см сосредоточено более $65 \%$ запасов корней. Отношение надземной фитомассы к корням в слое 0-40 см к августовскому сроку составило 1,4.

Таблица 2

\section{Запасы подземного растительного вещества в агроценозе рыжика посевного в слоях 0-20 и 20-40 см, т/га}

\begin{tabular}{|l|c|c|c|c|c|c|}
\hline \multirow{2}{*}{$\begin{array}{c}\text { Срок } \\
\text { отбора }\end{array}$} & \multicolumn{2}{|c|}{$\begin{array}{c}\text { Корни } \\
(\mathrm{X} \pm \mathrm{Sx})\end{array}$} & \multicolumn{2}{c|}{$\begin{array}{c}\text { Крупная } \\
\text { мортмасса }>0,5 \mathrm{~mm} \\
(\mathrm{X} \pm \mathrm{Sx})\end{array}$} & \multicolumn{2}{c|}{$\begin{array}{c}\text { Мелкая } \\
\text { мортмасса }<0,5 \mathrm{~mm} \\
(\mathrm{X} \pm \mathrm{Sx})\end{array}$} \\
\cline { 2 - 7 } & $0-20$ & $20-40$ & $0-20$ & $20-40$ & $0-20$ & $20-40$ \\
\hline Май & 0 & 0 & $3,25 \pm 0,19$ & $0,89 \pm 0,06$ & $1,48 \pm 0,03$ & $1,37 \pm 0,07$ \\
\hline Июнь & $0,08 \pm 0,004$ & $0,03 \pm 0,003$ & $2,10 \pm 0,36$ & $0,04 \pm 0,002$ & $2,18 \pm 0,16$ & $0,35 \pm 0,05$ \\
\hline Июль & $0,65 \pm 0,06$ & $0,41 \pm 0,01$ & $5,59 \pm 0,52$ & $1,00 \pm 0,12$ & $2,15 \pm 0,21$ & $0,86 \pm 0,13$ \\
\hline Август & $1,40 \pm 0,07$ & $0,68 \pm 0,05$ & $4,82 \pm 0,39$ & $1,73 \pm 0,04$ & $1,39 \pm 0,17$ & $1,00 \pm 0,09$ \\
\hline
\end{tabular}


Запасы крупной мортмассы представлены растительными остатками предыдущих лет и свежими порциями растительного материала, поступающего с поверхности в течение данного вегетационного сезона. Крупная мортмасса, находясь внутри почвы, претерпевает ряд изменений, связанных с ее перемешиванием и измельчением почвенной мезофауной, а также во время осенней и предпосевной обработки, частичным разложением и переходом в состав мелкой мортмассы. Такая трансформация сказывается на динамике этой фракции в почве.

В слое 0-20 см прослеживается волнообразная динамика запасов крупной мортмассы. При возделывании рыжика запасы крупной мортмассы в начале вегетации были 3,25 т/га, в июне ее запасы снизились до 2,1 т/га. В июле, напротив, достигли своего максимума - 5,59 т/га. К августу запасы крупной мортмассы незначительно снизились - до 4,82 т/га. В слое 20-40 см запас крупной мортмассы резко сокращается к июльскому сроку до 0,04 т/га, а к августу снова увеличивается до 1,73 т/га. Такой характер динамики запасов крупной мортмассы связан с поступлением надземных остатков в почву.

Отмирающие корни и крупная мортмасса являются пластическим материалом для пополнения запасов мелкой мортмассы. Ее запасы в слоях 0-20 и 20-40 см имеют тенденцию к по- степенному снижению в течение вегетационного сезона. Мелкая мортмасса формируется из крупной мортмассы и корней постепенно, представляя собой частично гумиффицированные растительные остатки или так называемое лабильное органическое вещество. Эта фрракция может одновременно пополняться за счет новых порций свежего опада, а также активно участвовать в процессах минерализации и гумисрикации, при этом ее запасы существенно сокращаются [5-8]. Средний запас мелкой мортмассы в слое 0-20 см - 1,8 т/га, в слое 20-40 см 0,9 т/га. Таким образом, в течение вегетации при возделывании рыжика в среднем в почве формируется запас мортмассы, равный 7,6 т/га, включая запасы мелкой мортмассы - 2,7 т/га. Причем большая часть этих остатков (65-81 \%) сосредоточена в слое 0-20 см.

К концу вегетации значительную долю в структуре подземного растительного вещества агроценоза занимает крупная мортмасса, еe доля составила в слое 0-20 cm 64 \%, в слое 20$40 \mathrm{~cm}-51 \%$ от всех запасов (рис. 2). Наименьшая доля от всех запасов подземного растительного вещества принадлежала корням рыжика как в слое 0-20, так и в слое 20-40 см. Такая закономерность связана с биологическими особенностями культуры.

$$
0-20 \mathrm{~cm}
$$

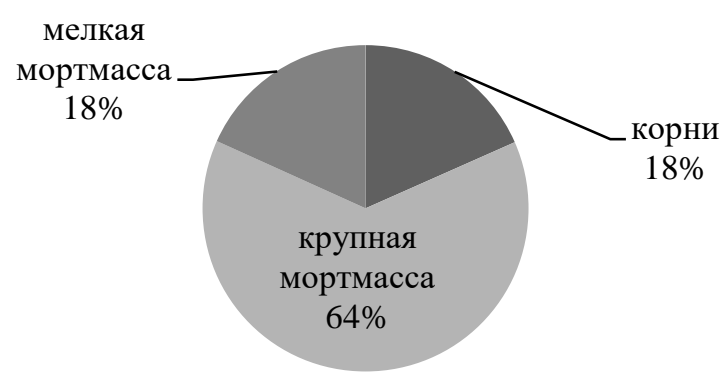

$20-40 \mathrm{~cm}$

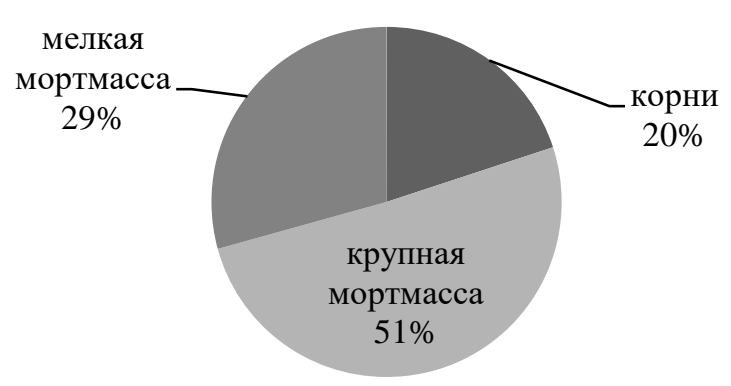

Puc. 2. Структура подземного растительного вещества в агроценозе рыжика посевного

Еще одной особенностью формирования запасов растительного вещества в агроценозе рыжика является увеличение к концу вегетации запасов мелкой мортмассы в слое почвы
20-40 см, что имеет огромное значение для формирования гумусового профиля почв и благоприятных условий корнеобитаемого пространства. 
Выводы. В структуре надземного растительного вещества преобладали запасы фитомассы рыжика, их доля к концу вегетации составила 70 \% (2,9 т/га). Доля запасов надземной мортмассы в это время была $12 \%$, или 0,5 т/га. В структуре подземного растительного вещества в слоях 0-20 и 20-40 см к уборке культуры преобладала крупная мортмасса, запасы которой были 4,8 и 1,7 т/га соответственно. Запасы корней составили 2,1 т/га. Запасы мелкой мортмассы в среднем за вегетацию в слое 0-20 см составили 1,8 т/га; в слое 20-40 см - 0,9 т/га.

\section{Литература}

1. Семенов В.М., Когут Б.М. Почвенное органическое вещество. - М.: ГЕОС, 2015. - 233 с.

2. Базилевич Н.И. Биологическая продуктивность экосистем Северной Евразии. - М.: Наука, 1993. - 293 с.

3. Кирюшин В.И. Экологические основы земледелия. - М.: Колос, 1996. - 367 с.

4. Чупрова В.В, Люкшина И.В., Белоусов А.А. Запасы и динамика легкоминерализуемой фракции органического вещества в почвах Средней Сибири // Вестн. КрасГАУ. 2003. - № 3. - С. 65.

5. Тейт P. Органическое вещество почв: биологические и экологические аспекты. - М: Мир, 1991. - 400 c.

6. Титлянова, А.А., Чупрова В.В. Изменение круговорота углерода в связи с различным использованием земель (на примере Красноярского края) // Почвоведение. - 2003. № 2. - C. 211-219.

7. Шарков И.Н., Самохвалова Л.М., Мишина П.В., Шепелев А.Г. Влияние пожнивных остатков на состав органического вещества чернозема выщелоченного в лесостепи Западной Сибири // Почвоведение. - 2014. - № 4. C. $473-479$.
8. Власенко О.А., Аветисян А.Т. Запасы растительного вещества в агроценозах многолетних кормовых трав Красноярской лесостепи // Вестн. КрасГАУ. - 2015. - № 10. C. 126-131.

\section{Literatura}

1. Semenov V.M., Kogut B.M. Pochvennoe organicheskoe veshchestvo. - M.: GEOS, 2015. - $233 \mathrm{~s}$.

2. Bazilevich N.I. Biologicheskaya produktivnost' ekosistem Severnoj Evrazii. - M.: Nauka, 1993. - $293 \mathrm{~s}$.

3. Kiryushin V.I. Ekologicheskie osnovy zemledeliya. - M.: Kolos, 1996. - $367 \mathrm{~s}$.

4. CHuprova V.V, Lyukshina I.V., Belousov A.A. Zapasy i dinamika legkomineralizuemoj frakcii organicheskogo veshchestva $v$ pochvah Srednej Sibiri // Vestn. KrasGAU. - 2003. № 3. - S. 65.

5. Tejt $R$. Organicheskoe veshchestvo pochv: biologicheskie i ekologicheskie aspekty. - M: Mir, 1991. - $400 \mathrm{~s}$.

6. Titlyanova, A.A., CHuprova V.V. Izmenenie krugovorota ugleroda $v$ svyazi $s$ razlichnym ispol'zovaniem zemel' (na primere Krasnoyarskogo kraya) // Pochvovedenie. 2003. - № 2. - S. 211-219.

7. SHarkov I.N., Samohvalova L.M., Mishina P.V., SHepelev A.G. Vliyanie pozhnivnyh ostatkov na sostav organicheskogo veshchestva chernozema vyshchelochennogo v lesostepi Zapadnoj Sibiri // Pochvovedenie. 2014. - № 4. -S. 473-479.

9. Vlasenko O.A., Avetisyan A.T. Zapasy rastitel'nogo veshchestva $\mathrm{v}$ agrocenozah mnogoletnih kormovyh trav Krasnoyarskoj lesostepi // Vestn. KrasGAU. - 2015. - № 10. S. 126-131. 